\title{
Cell Proliferation Ability of Mouse Fibroblast-Like Cells and Osteoblast-Like Cells on a Ti-6Al-4V Alloy Film Produced by Selective Laser Melting
}

\author{
Mayu Kawase', Tatsuhide Hayashi'1,2*, Masaki Asakura1, Akimichi Mieki', \\ Hironari Fuyamada ${ }^{3}$, Masahiro Sassa ${ }^{2,4}$, Shizuka Nakano ${ }^{2,5}$, Masashi Hagiwara2,4, \\ Toru Shimizu 2,5 , Tatsushi Kawai ${ }^{1}$ \\ ${ }^{1}$ Department of Dental Materials Science, Aichi Gakuin University School of Dentistry, Nagoya, Japan \\ ${ }^{2}$ Advanced Laser and Process Technology Research Association (ALPROT), Tokyo, Japan \\ ${ }^{3}$ Department of Gerodontology, Aichi Gakuin University School of Dentistry, Nagoya, Japan \\ ${ }^{4}$ Laser Sintering Department, ASPECT Inc., Tokyo, Japan \\ ${ }^{5}$ Low-Formability-Materials Processing Group, Advanced Manufacturing Research Institute, National Institute \\ of Advanced Industrial Science and Technology, Tsukuba, Japan \\ Email: ${ }^{*}$ thayashi@dpc.agu.ac.jp
}

Received 31 March 2014; revised 2 May 2014; accepted 13 May 2014

Copyright (C) 2014 by authors and Scientific Research Publishing Inc.

This work is licensed under the Creative Commons Attribution International License (CC BY).

http://creativecommons.org/licenses/by/4.0/

(c) (i) 0 pen Access

\section{Abstract}

Successful regeneration of tissues and organs relies on the application of suitable substrates or scaffolds in scaffold-based regenerative medicine. In this study, Ti-6Al-4V alloy films (Ti alloy film) were produced using a three-dimensional printing technique called Selective Laser Melting (SLM), which is one of the metal additive manufacturing techniques. The thickness of produced Ti alloy film was approximately $250 \mu \mathrm{m}$. The laser-irradiated surface of Ti alloy film had a relatively smooth yet porous surface. The non-irradiated surface was also porous but also retained a lot of partially melted Ti-6Al-4V powder. Cell proliferation ability of mouse fibroblast-like cells (L929 cells) and mouse osteoblast-like cells (MC3T3-E1 cells) on both the surfaces of Ti alloy film was examined using WST assay. Both L929 and MC3T3-E1 cells underwent cell proliferation during the culture period. These results indicate that selective laser melting is suitable for producing a cell-compatible Ti-6Al-4V alloy film for biomaterials applications.

\section{Keywords}

Selective Laser Melting (SLM), Ti-6Al-4V Film, Mouse Fibroblast-Like Cell, Mouse Osteoblast-Like

\footnotetext{
"Corresponding author.
}

How to cite this paper: Kawase, M., et al. (2014) Cell Proliferation Ability of Mouse Fibroblast-Like Cells and Osteoblast-Like Cells on a Ti-6Al-4V Alloy Film Produced by Selective Laser Melting. Materials Sciences and Applications, 5, 475-483. 


\section{Cell, Cell Compatibility}

\section{Introduction}

General clinical approaches in dentistry and medicine to the problems of injury, disease, or non-functional tissue/organ include reconstructive surgery and transplantation of artificial materials [1]. Tissue engineering (TE) is one method used to regenerate damaged tissues/organs using cell-seeded scaffolds, which may be fabricated from ceramics, synthetic polymers and metals [1] [2]. Scaffolds for TE must have good biocompatibility, a highly porous and interconnected structure to allow cell migration, and mechanical properties that match those of the host tissue/organ [2] [3]. Collagen, hydrogels, poly(l-lactic acid) and polyglycoric acid are used in applications that call for biodegradable scaffolds [1] [4]-[6]. Meanwhile, metals are typical non-biodegradable scaffolds, and there for are especially required to have an excellent biocompatibility and low allergic reactions. Although metal deterioration and corrosion sometimes are problems after transplantation, metals are still effective transplantation materials because of its physical strength surpass other materials [7] [8]. Titanium (Ti), for example, has excellent biocompatibility and corrosion resistance so has been used extensively in dental implants and orthopedic prostheses, such as hips and knees [9] [10].

TE scaffolds can be fabricated by selective laser melting (SLM), electron beam melting (EBM) and fused deposition modeling (FDM), which are three-dimensional additive manufacturing (AM) techniques [11]-[15]. Using computer-aided design (CAD) to construct the material layer-by-layer, these AM techniques are capable of fabricating structures with a patient-specific architecture [16]. To improve fixation and stability of dental and orthopedic implants, porous coatings are being developed that promote mechanical inter locking by osteoblast proliferation and bone ingrowth. Porous Ti films are one such example that is expected to have substantial clinical applications.

In this study, Ti-6Al-4V film was produced using SLM; three-dimensional printing technique, and then cell proliferation ability was examined of mouse fibroblast-like cells to confirm the cell compatibility on the Ti-6Al-4V film. Furthermore, it is assumed that this Ti-6Al-4V film will be clinically applied for regeneration of bone defects as a scaffold in the near future, cell proliferation ability and calcification ability of mouse osteoblast-like cells were examined.

\section{Materials and Methods}

\subsection{Ti-6Al-4V Powders}

The chemical composition of the Ti-6Al-4V powder (TILOP64-150; OSAKA Titanium Technologies Co., Ltd., Hyogo, Japan) used in this study is listed in Table 1. The average particle size was approximately $80 \mu \mathrm{m}$.

\subsection{Production of Ti-6Al-4V Film by SLM}

The process parameters of the SLM apparatus (RafaEl $150 \mathrm{~V}$; ASPECT Inc., Tokyo, Japan) used to produce the Ti-6Al-4V film (Ti alloy film) are listed in Table 2 . The volumetric energy density E $\left(\mathrm{J} \mathrm{mm}^{-3}\right)$ was calculated as:

$$
\mathrm{E}=\mathrm{P} / \mathrm{vdh}
$$

where $\mathrm{P}$ is the laser power $(\mathrm{W}), \mathrm{v}$ is the scanning speed $(\mathrm{mm} / \mathrm{s}), \mathrm{h}$ is the hatch spacing $(\mathrm{mm})$ and $\mathrm{d}$ is the layer thickness (mm).

Production of Ti alloy film was carried out under vacuum conditions $\left(10^{-2} \mathrm{~Pa}\right)$ to avoid oxidation. The powder bed was kept at a preheated temperature of $150^{\circ} \mathrm{C}$ to reduce the residual stresses that might develop during the process. In the fabrication of the first layer, the laser power began at $80 \mathrm{~W}$, increased in increments of $6 \mathrm{~W}$ until it reached $200 \mathrm{~W}$. Subsequent layers were added under the same conditions to produce the film structure.

Table 1. Chemical composition of the Ni-6Al-4V powder (Tilop64-150).

\begin{tabular}{cccccccccc}
\hline Elements & $\mathbf{O}$ & $\mathbf{H}$ & $\mathbf{N}$ & $\mathbf{C}$ & $\mathbf{F e}$ & $\mathbf{A l}$ & $\mathbf{\text { Ti }}$ \\
\hline $\mathbf{w t} \%$ & 0.20 & 0.015 & 0.05 & 0.08 & 0.40 & $5.5 \sim 6.75$ & $3.5 \sim 4.5$ & Bal. \\
\hline
\end{tabular}


Table 2. Selective laser melting parametes.

\begin{tabular}{cc}
\hline Parameter & Value \\
\hline Degree of vacuum $(\mathrm{Pa})$ & $10^{-2}$ \\
Laser power $(\mathrm{W})$ & 200 \\
Layer thickness $(\mathrm{mm})$ & 0.2 \\
Hatch spacing $(\mathrm{mm})$ & 0.08 \\
Scanning speed $(\mathrm{mm} / \mathrm{s})$ & 2000 \\
Scanning area dimensions $(\mathrm{mm} \times \mathrm{mm})$ & $10 \times 30$ \\
\hline
\end{tabular}

Created from this process, the produced Ti alloy film has two surfaces, laser-irradiated (top) and non-irradiated (bottom).

\subsection{Preparation of Samples}

The Ti alloy film was formed into circles of $10 \mathrm{~mm}$ diameter for testing. The circular films were washed with synthetic detergent, ultrasonically cleaned for $20 \mathrm{~min}$, then sterilized with ethylene oxide gas for $22 \mathrm{~h}$.

\subsection{Observation of Surface Property of Ti Alloy Film}

Scanning electron microscopy (SEM; JSM-5510; JEOL, Tokyo, Japan) was used to observe the surface properties of both laser-irradiated surface and non-irradiated surface of Ti alloy films. The specimens were vapor deposited with carbon and observed at an accelerating voltage of $5 \mathrm{kV}$. Moreover, three-dimensional laser scanning microscope (VK-X200, Keyence, Osaka, Japan) was used to measure the calculated average roughness (Ra) of both surfaces. The surface area was measured in an approximately $2860 \times 3940 \mu \mathrm{m}$ horizontal plane.

\subsection{Measurement of Wettability}

The Wettability of both laser-irradiated surface and non-irradiated surface was assessed by measuring the contact angle (Sensiv Measure, Mitani Corporation, Tokyo, Japan) of $50 \mu \mathrm{L}$ of distilled water placed on the Ti alloy film $(n=3)$.

\subsection{Cell Culture}

In this study, fibroblast-like cells (L929; NCTC clone 929, Connective tissue, mouse; DS pharma Biomedical Co., Osaka, Japan) and osteoblast-like cells (MC3T3-E1; Calvaria, mouse; DS pharma Biomedical Co.) were used. L929 cells were cultured in Eagle's Minimal Essential Medium (Life Technologies, Grand Island, NY, USA) with 5\% fetal bovine serum (FBS; Life Technologies), penicillin (100 units $/ \mathrm{mL}$; Life Technologies) and streptomycin $\left(100 \mu \mathrm{g} / \mathrm{mL}\right.$; Life Technologies) in a humidified atmosphere with $5 \% \mathrm{CO}_{2}$ until confluent at $37^{\circ} \mathrm{C}$. MC3T3-E1 cells were cultured in Alpha-Eagle's Minimal Essential Medium (Life Technologies) with 10\% FBS, penicillin (100 units $/ \mathrm{mL}$; Life Technologies) and streptomycin $(100 \mu \mathrm{g} / \mathrm{mL}$; Life Technologies) in the same conditions.

\subsection{Cell Proliferation Tests}

Each laser-irradiated surface and non-irradiated surface of Ti alloy film was placed in a 48-well micro-plate. The cells were suspended at $1 \times 10^{5}$ cells $/ \mathrm{mL}$ in each medium and seeded at $400 \mu \mathrm{L} /$ well. The cells seeded on a micro-plate directly as a negative control. All culture media were changed every 2 days. The culture period for L929 cells was 5 days and cell proliferation was measured each day $(n=3)$. The culture period for MC3T3-E1 cells was 10 days and measurements of cell proliferation were carried out on days 2, 4, 6, 8 and $10(n=3)$. The cell proliferation at each time point was measured by the WST assay using a Cell Counting Kit-8 (Dojindo Laboratories, Kumamoto, Japan; OD at $450 \mathrm{~nm}$ ).

\subsection{Observation of Cell Morphology of Cells}

To observe their post-culture morphology, the L929 and MC3T3-E1 cell samples were fixed with 2\% glutaral- 
dehyde (TAAB Laboratories Equipment Ltd., Aldermaston, UK) for $24 \mathrm{~h}$, post-fixed in $1 \%$ osmium tetraoxide (TAAB Laboratories Equipment Ltd.) for $3 \mathrm{~h}$, dehydrated through a series of alcohols and then freeze-dried. Finally, the samples were sputter-coated with platinum and observed using SEM at $10 \mathrm{kV}$. The cell morphology of L929 cells was observed on days 1, 2 and 3, and that of MC3T3-E1 cells was observed on days 1, 4, 7, 10 and 13.

\subsection{Alizarin Red S Staining}

Alizarin Red S staining was performed on days 14, 21 and 28 to detect mineral deposition caused by MC3T3-E1 cells. The cells on each Ti alloy film were washed with PBS three times and then fixed with ethanol for 20 min at $4{ }^{\circ} \mathrm{C}$. Next, the cells were washed with distilled water three times and exposed to $0.01 \%$ Alizarin Red S solution (Calcified nodule Staining kit; Primary Cell Co., Ltd., Sapporo, Japan) for $5 \mathrm{~min}$ at room temperature. After staining, the cells were washed with buffer solution to eliminate non-specific staining.

\subsection{Statistical Analysis}

To evaluate cell proliferation of L929 and MC3T3-E1 cells on Ti alloy film, we performed one-factor ANOVA followed by Tukey's post hoc test. P-values of less than 0.05 were considered to be statistically significant. All values are expressed as the mean \pm standard deviation ( $\mathrm{M} \pm$ S.D.).

\section{Results and Discussion}

\subsection{Morphological Characterization of Produced Ti Alloy Film}

SLM is a three-dimensional printing technique, and this technique was used to produce Ti alloy film in this study. This AM technique allows the generation of complex three-dimensional metal parts by selectively melting successive layers of metal powder on top of each other, using the thermal energy supplied by a focused and computer-controlled laser beam [11] [12].

Macroscopic and SEM images of the Ti alloy film and three-dimensional surface topographies are shown in Figure 1. The film thickness was approximately $250 \mu \mathrm{m}$. The laser-irradiated surface was relatively smooth with large numbers of pores (approximately $100-200 \mu$ min diameter) although these did not penetrate to the opposite side. On the other hand, the non-irradiated surface, also porous yet rough, was distinguished by partially melted Ti-6Al-4V powder. The calculated average roughness $(\mathrm{Ra})$ of laser-irradiated surface was $2.336 \mu \mathrm{m}$ and that of non-irradiated surface was $7.791 \mu \mathrm{m}$.

\subsection{Wettability Test}

Figure 2 shows side-view images of $50 \mu \mathrm{L}$ of distilled water placed on the laser-irradiated and the non-irradiated surfaces. Their respective contact angles were approximately $91.3^{\circ}$ and $97.9^{\circ}$. There was no significant difference between the two groups.

Neither the laser-irradiated nor non-irradiated surfaces showed high hydrophilicity. It has been reported that hydrophilicity of the Ti disk surface may be gradually lost through hydrocarbon contamination and causing hydrophobicity [17] [18]. However, hydrocarbon contamination was removed by $48 \mathrm{~h}$ ultraviolet treatment, and obtained a super hydrophilic surface as a result [18]. Therefore, it is suggested that Ti alloy film produced in this study had been contaminated by hydrocarbon or other chemicals, and it may be necessary to remove these contaminates to obtain a clean and hydrophilic surface.

\subsection{Cell Proliferation and Cell Morphology}

Cell proliferation was measured in both L929 and MC3T3-E1 cells throughout the culture period.

L929 cells cultured on the control micro-plate reached confluence after 5 days. Their proliferation on the Ti alloy film was slower than that of control, not reaching confluence, and did not show a statistically significant difference between the laser-irradiated surface group and non-irradiated surface group in the first 4 days of culture (Figure 3(a)).

MC3T3-E1 cells cultured on the control reached confluence on day 10. As with the L929 cells, the proliferation of MC3T3-E1 cells on the Ti alloy film was slower than on the control, also not reaching confluence. There 
(a) Macroscopic image
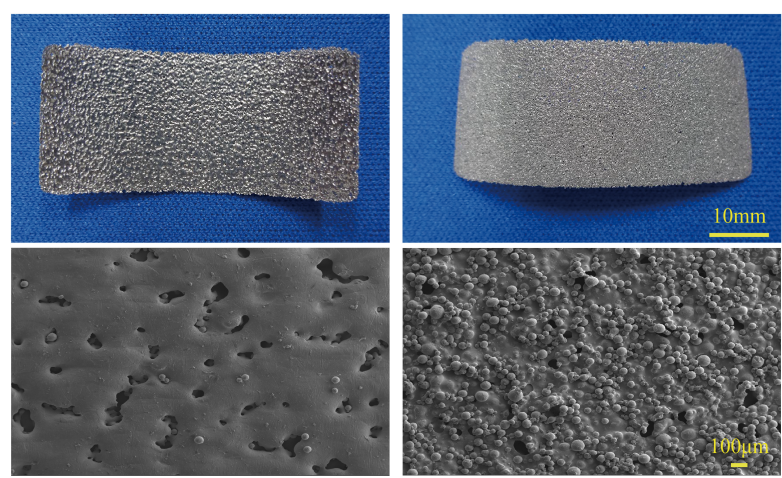

(b) SEM image

(c) Surface topography
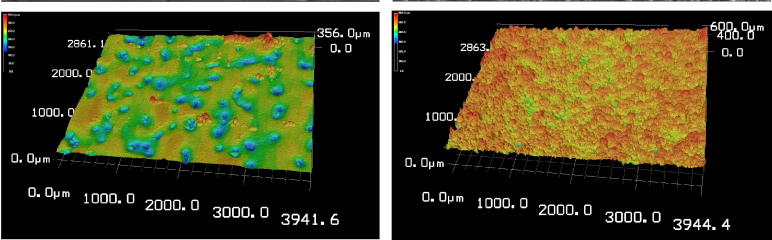

Laser-irradiated surface

Non-irradiated surface

Figure 1. Macroscopic (a) and SEM images (b) and three-dimensional surface topographies (c) of the Ti-6Al-4V alloy film. The thickness was approximately $250 \mu \mathrm{m}$. The laser-irradiated surface was relatively smooth yet porous. The non-irradiated surface contains a lot of pores, but it was rough and partially melted Ti-6Al-4V powder. The calculated average roughness $(\mathrm{Ra})$ of laser-irradiated surface was $2.336 \mu \mathrm{m}$ and that of non-irradiated surface was $7.791 \mu \mathrm{m}$.

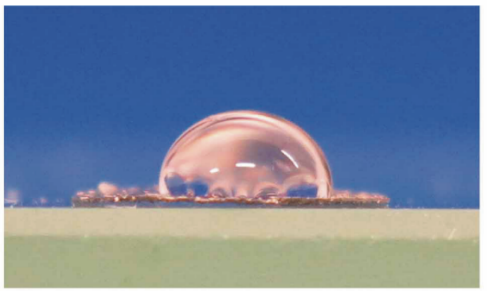

Laser-irradiated surface

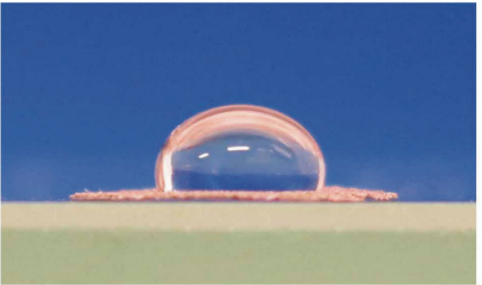

Non-irradiated surface

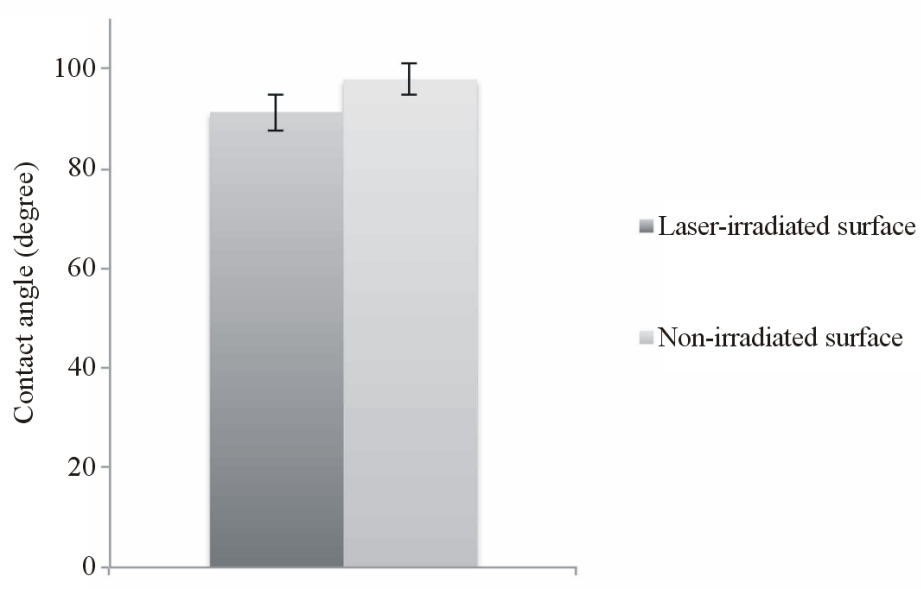

Figure 2. Wettability test of Ti-6Al-4V alloy film. Side-view images of distilled water placed on both the laser-irradiated surface and the non-irradiated surface of Ti alloy film. Their respective contact angles were approximately $91.3^{\circ}$ and $97.9^{\circ}$. Data are shown as mean \pm S.D. (error bar). 
was not a significant difference between the control and experimental groups. Meanwhile, there showed a significant difference only on the day 8 by the comparison in the experimental groups (Figure 3(b)).

SEM images of the typical cell morphologies on the Ti alloy film are shown in Figure 4.

The cells were polygonal and spindle-shaped and the cytoskeleton was well developed in the laser-irradiated and non-irradiated surface groups. The L929 and MC3T3-E1 cells had a similar appearance.

The porous nature of the laser-irradiated and non-irradiated surfaces and the partially melted Ti-6Al-4V powder on the non-irradiated surface were expected to act as anchors, thereby accelerating cell proliferation. However, this was not the case. By UV-treating the Ti alloy surface, in addition to becoming super hydrophilic, it has been demonstrated that such surfaces display enhanced attachment, spread, proliferation and differentiation of osteoblasts, as well as increased protein absorption in vitro [18]. We submit that our Ti alloy film requires a similar surface modification to promote cell proliferation.

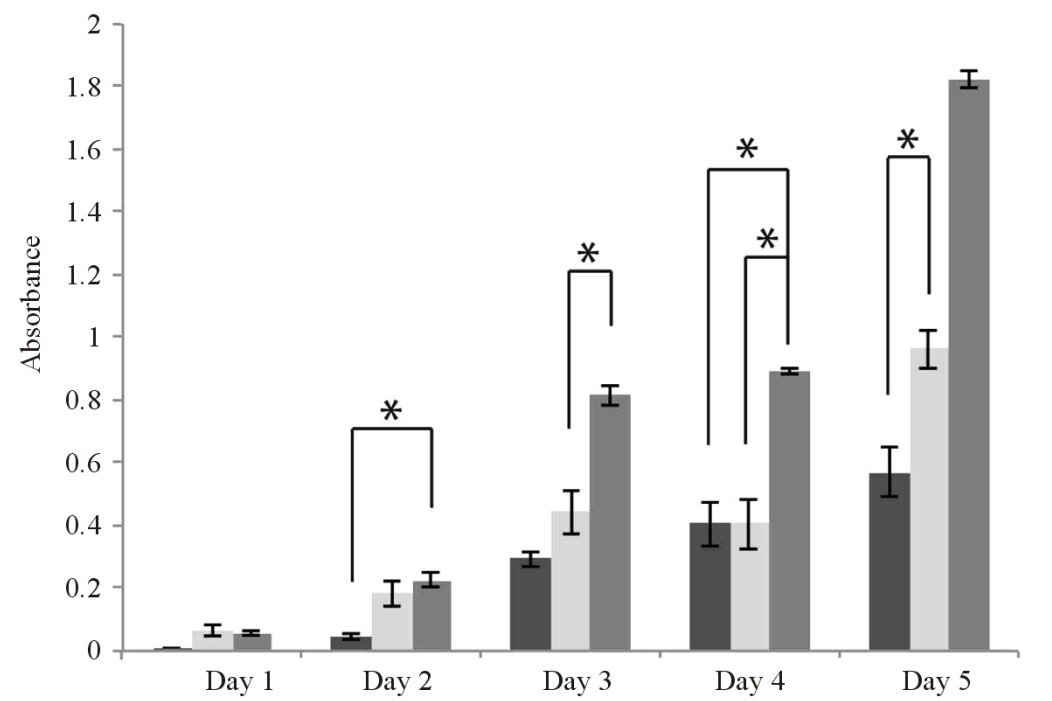

(a)

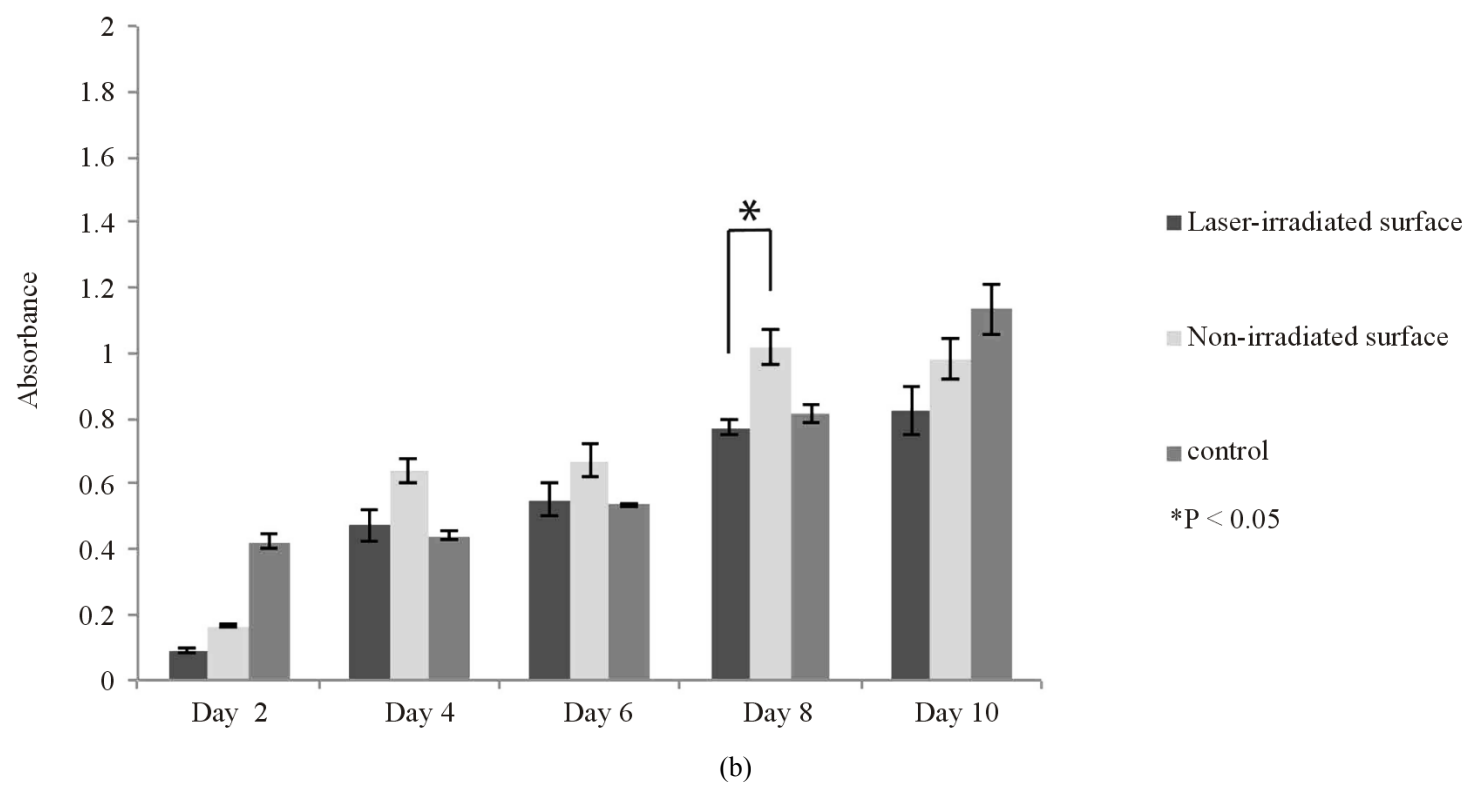

Figure 3. Cell proliferation of the L929 (a) and MC3T3-E1 (b) cells on the laser-irradiated and non-irradiated Ti-6Al-4V alloy films and on a control plate. Proliferation was more rapid on the control but both cells gradually proliferated throughout the culture period on the Ti-6Al-4V alloy films. Data are shown as mean \pm S.D. (error bars). 
On the other hand, guided tissue regeneration (GTR) or guided bone regeneration (GBR) are one of the methods to regenerate absorbed alveolar bone in periodontics. In this method, biodegradable membranes (polylactic acid/polyglycolicacid copolymer and collagen) or non-biodegradable membrane (expanded polytetrafluoroethylene) are used to prevent in-growth of epithelial tissue or connective tissue which have a higher proliferation potential than osteoblasts [19]-[21]. These GTR/GBR membranes have the required flexibility to maintain the form of regenerated alveolar bone and mechanical strength that can tolerate external forces. Therefore, it is also suggested that this Ti alloy film has a possibility to be applied as the other biomedical materials.

\subsection{Alizarin Red S Staining}

The results of Alizarin Red S staining of MC3T3-E1 cells are shown in Figure 5. The red region on the Ti alloy film indicates calcium deposition. A slight deposition was observed from day 14, caused by the MC3T3-E1. However, this calcium deposition level became gradually remarkable. These results indicate that our Ti alloy film facilitates the proliferation of MC3T3-E1 cells. There was no noticeable difference between the laser-irradiated and non-irradiated surfaces.

L929

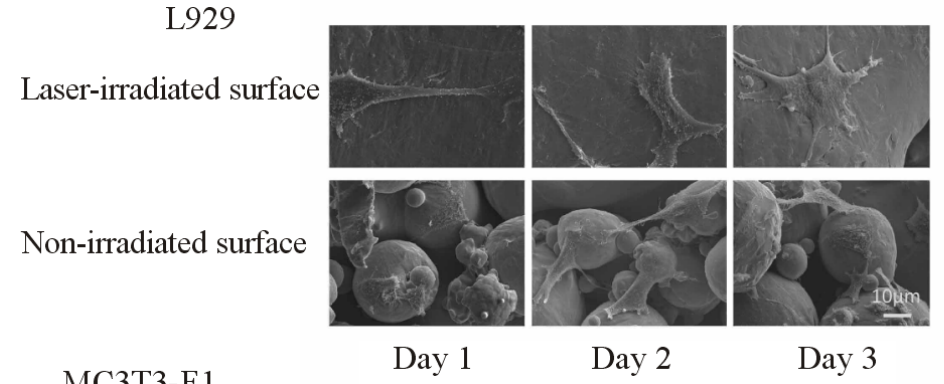

MC3T3-E1

Day 1

Day 2

Day 3

Laser-irradiated surface
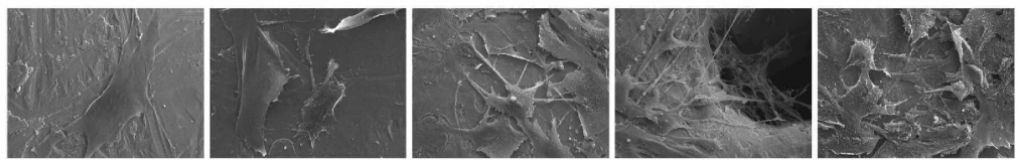

Non-irradiated surface
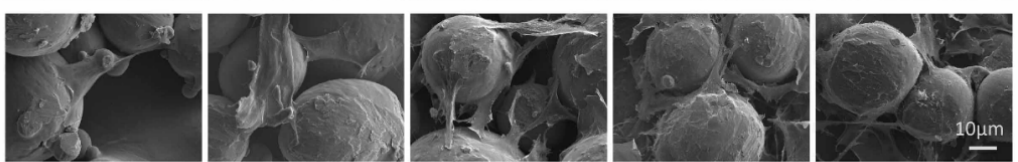

Day 1

Day 4

Day 7

Day 10

Day 13

Figure 4. SEM observation of cell morphology of L929 and MC3T3-E1 cells on the Ti-6Al-4V alloy film. Both cell types were polygonal and spindle-shaped on the laser-irradiated and non-irradiated surfaces.

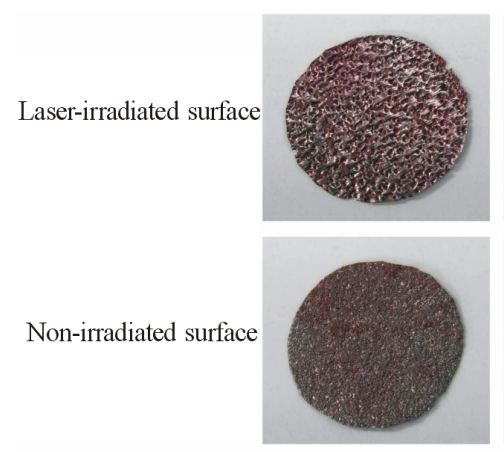

Day 14

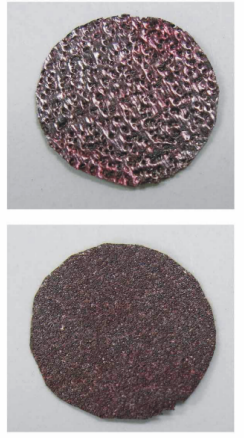

Day 21

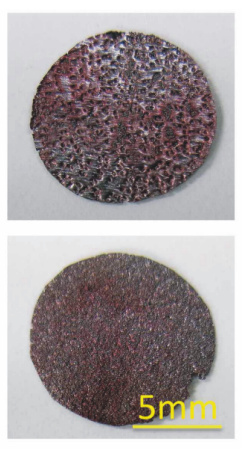

Day 28

Figure 5. An Alizarins Red S staining of MC3T3-E1 cells on the Ti-6Al-4V alloy film. Calcium deposition level became gradually remarkable during the culture period. There was no noticeable difference between the laser-irradiated and non-irradiated surfaces. 


\section{Conclusion}

In this study, we tested the cell proliferation ability of Ti-6Al-4V alloy films produced by selective laser melting. Both L929 and MC3T3-E1 cells underwent proliferation during the culture period, independent of whether the Ti-6Al-4V alloy surface was laser-irradiated or non-irradiated. These results indicate that selective laser melting is a suitable technique for producing cell-compatible scaffolding surfaces. Furthermore, it may also be widely applied as a biomedical material in the near future.

\section{Acknowledgements}

The three-dimensional additive manufacturing machine used in this study was developed in the "Laser Material Processing Technology Development Project for Next-generation Materials, Etc" of the New Energy and Industrial Technology Development Organization (NEDO).

\section{Conflict of Interests}

No benefit of any kind will be received either directly or indirectly by the authors.

\section{References}

[1] Tabata, Y. (2004) Tissue Regeneration Based on Tissue Engineering Technology. Congenital Anomalies (Kyoto), 44, 111-124. http://dx.doi.org/10.1111/j.1741-4520.2004.00024.x

[2] Langer, R. and Vacanti, J.P. (1993) Tissue Engineering. Science, 260, 920-926. http://dx.doi.org/10.1126/science.8493529

[3] Warnke, P.H., Douglas, T., Wollny, P., Sherry, E., Steiner, M., Galonska, S., Becker, S.T., Springer, I.N., Witfang, J.W. and Sivananthan, S. (2009) Rapid Prototyping: Porous Titanium Alloy Scaffolds Produced by Selective Laser Melting for Bone Tissue Engineering. Tissue Engineering: Part C Methods, 15, 115-124. http://dx.doi.org/10.1089/ten.tec.2008.0288

[4] Kim, B.S., Nikolovski, J., Bonadio, J., Smiley, E. and Mooney, D.J. (1999) Engineered Smooth Muscle Tissues: Regulating Cell Phenotype with the Scaffold. Experimental Cell Research, 251, 318-328. http://dx.doi.org/10.1006/excr.1999.4595

[5] Ueki, K., Takazakura, D., Marukawa, K., Shimada, M., Nakagawa, K., Takatsuka, S. and Yamamoto, E. (2003) The Use of Polylactic Acid/Polyglycolic Acid Copolymer and Gelatin Sponge Complex Containing Human Recombinant Bone Morphogenetic Protein-2 Following Condylectomy in Rabbits. Journal of Cranio-Maxillofacial Surgery, 31, 107-114. http://dx.doi.org/10.1016/S1010-5182(02)00187-7

[6] Chen, G., Sato, T., Ohgushi, H., Ushida, T., Tateishi, T. and Tanaka, J. (2005) Culturing of Skin Fibroblasts in a Thin PLGA-Collagen Hybrid Mesh. Biomaterials, 26, 2559-2266. http://dx.doi.org/10.1016/j.biomaterials.2004.07.034

[7] Alvarez, K. and Nakajima, H. (2009) Metallic Scaffolds for Bone Regeneration. Materials, 2, 790-832. http://dx.doi.org/10.3390/ma2030790

[8] Jacobs, J.J., Skipor, A.K., Patterson, L.M., Hallab, N.J., Paprosky, W.G., Black, J. and Galante, J.O. (1998) Metal Release in Patients Who Have Had a Primary Total Hip Arthroplasty. A Prospective, Controlled, Longitudinal Study. The Journal of Bone and Joint Surgery, 80, 1447-1458.

[9] Barão, V.A.R., Mathew, M.T., Assunção, W.G., Yuan, J.C.-C., Wimmer, M.A. and Sukotjo, C. (2012) Stability of cpTi and Ti-6Al-4V Alloy for Dental Implants as a Function of Saliva pH-An Electrochemical Study. Clinical Oral Implants Research, 23, 1055-1062. http://dx.doi.org/10.1111/j.1600-0501.2011.02265.x

[10] Sarmiento-Gonzalez, A., Marchante-Gayon, J.M., Tejerina-Lobo, J.M., Paz-Jimenez, J. and Sanz-Medel, A. (2008) High-Resolution ICP-MS Determination of Ti, V, Cr, Co, Ni, and Mo in Human Blood and Urine of Patients Implanted with a Hip or Knee Prosthesis. Analiticaland Bioanalitical Chemistry, 391, 2583-2589. http://dx.doi.org/10.1007/s00216-008-2188-4

[11] Van Bae, S., Kerckhofs, G., Moesen, M., Pyka, G., Schrooten, J. and Kruth, J.P. (2011) Micro-CT-Based Improvement of Geometrical and Mechanical Controllability of Selective Laser Melted Ti6A14V Porous Structures. Materials Science and Engineering: A, 528, 7423-7431. http://dx.doi.org/10.1016/i.msea.2011.06.045

[12] Van Bael, S., Chai, Y.C., Truscello, S., Moesen, M., Kerckhofs, G., Van Oosterwyck, H., Kruth, J.-P. and Schrooten, J. (2012) The Effect of Pore Geometry on the in Vitro Biological Behavior of Human Periosteum-Derived Cells Seeded on Selective Laser-Melted Ti6Al4V Bone Scaffolds. Acta Biomateialia, 8, 2824-2834. http://dx.doi.org/10.1016/j.actbio.2012.04.001 
[13] Mullen, L., Stamp, R.C., Fox, P., Jones, E., Ngo, C. and Sutcliffe, C.J. (2010) Selective Laser Melting: A Unit Cell Approach for the Manufacture of Porous, Titanium, Bone In-Growth Constructs, Suitable for Orthopedic Applications. II. Randomized Structures. Journal of Biomedical Materials Research Part B: Applied Biomaterials, 92, 178-188. http://dx.doi.org/10.1002/jbm.b.31504

[14] Murr, L.E., Gaytan, S.M., Martinez, E., Medina, F. and Wicke, R.B. (2012) Next Generation Orthopaedic Implants by Additive Manufacturing Using Electron Beam Melting. International Journal of Biomaterials, 2012, 1-14. http://dx.doi.org/10.1155/2012/245727

[15] Korpela, J., Kokkari, A., Korhonen, H., Malin, M., Narhi, T. and Seppala, J. (2013) Biodegradable and Bioactive Porous Scaffold Structures Prepared Using Fused Deposition Modeling. Journal of Biomedical Materials Research Part B: Applied Biomaterials, 101, 610-619. http://dx.doi.org/10.1002/jbm.b.32863

[16] Wong, K.C., Kumta, S.M., Sze, K.Y. and Wong, C.M. (2012) Use of a Patient-Specific CAD/CAM Surgical Jig in Extremity Bone Tumor Resection and Custom Prosthetic Reconstruction. Computer Aided Surgery, 17, 284-293. http://dx.doi.org/10.3109/10929088.2012.725771

[17] Att, W., Hori, N., Takeuchi, M., Ouyang, J., Yang, Y., Anpo, M. and Ogawa, T. (2009) Time-Dependent Degradation of Titanium Osteoconductivity: An Implication of Biological Aging of Implant Materials. Biomaterials, 30, 5352-5363. http://dx.doi.org/10.1016/j.biomaterials.2009.06.040

[18] Aita, H., Hori, N., Takeuchi, M., Suzuki, T., Yamada, M., Anpo, M. and Ogawa, T. (2009) The Effect of Ultraviolet Functionalization of Titanium on Integration with Bone. Biomaterials, 30, 1015-1025. http://dx.doi.org/10.1016/j.biomaterials.2008.11.004

[19] Bunyaratavej, P. and Wang, H. L. (2001) Collagen Membranes: A Review. Journal of Periodontology, 72, $215-229$. http://dx.doi.org/10.1902/jop.2001.72.2.215

[20] Stavropoulos, A., Sculean, A. and Karring, T. (2004) GTR Treatment of Intrabony Defects with PLA/PGA Copolymer or Collagen Bioresorbable Membranes in Combination with Deproteinized Bovine Bone (Bio-Oss). Clinical Oral Investigations, 8, 226-232. http://dx.doi.org/10.1007/s00784-004-0277-0

[21] Teparat, T., Solt, C.W., Claman, L.J. and Beck, F.M. (1998) Clinical Comparison of Bioabsorbable Barriers with NonResorbable Barriers in Guided Tissue Regeneration in the Treatment of Human Intrabony Defects. Journal of Periodontology, 69, 632-641. http://dx.doi.org/10.1902/jop.1998.69.6.632 